\title{
The Role of Environmental Justice in Biodiversity Conservation: Investigating Experiences of Communities near Kruger National Park, South Africa
}

\begin{abstract}
This paper uses an environmental justice framework to examine the experiences of marginalized communities near Kruger National Park. While biodiversity conservation has been predominantly understood as a neutral and ahistorical objective, a critical perspective reveals that a range of power relations inform its definitions and processes. Further, the spaces in which conservation efforts are undertaken are vulnerable to reproducing inequalities of the larger society in which they are situated. I establish biodiversity conservation in Kruger as an environmental justice issue and frame the discussion regarding communities near the Park within the categories of (a) land ownership and resource use, (b) community participation in park management and decision-making, and (c) justly shared economic and socio-cultural benefits. While improvements have occurred, the maintenance of Kruger requires integrating an environmental justice perspective to its programs and a more meaningful partnership with surrounding marginalized communities to ensure equitable use and benefits of the Park.
\end{abstract}

\begin{abstract}
About the Author(s): Catherine Hart is a student in the School for Resource and Environmental Studies and a candidate for the Masters of Resource and Environmental Management. Her passion for environmental justice led her to explore biodiversity conservation while enrolled in the Conservation System Design class. The paper was originally written as an assignment for this class and was presented at the Atlantic Canadian Association of Geographers Annual Meeting on October 20, 2012.
\end{abstract}




\section{Introduction}

In many contexts, the concept of environmental justice has yet to be appropriately applied with respect to biodiversity conservation. Individual and collective identities inform experiences of living in diverse ways and contribute to people finding different meanings in how they experience their surroundings. I use the concept of "surroundings" developed by scholars West, lgoe, and Brockington (2006) because it reflects the evolution of the term "environment," which has achieved the recognition that behaviours of all organisms within an ecosystem influence each other. It combines what these authors (West, Igoe, \& Brockington, 2006) identify as the "social construction of nature" and the "material nature of the environment" (p. 252). Therefore, ideas about conservation, land, resource use, and ecosystem services cannot be constructed without bias, but are reproduced from within variant places/spaces and influenced by power relations of organisms operating therein.

From the position that biodiversity conservation is not a neutral process, I provide a brief contextual background of environmental justice. I then assess its relevance to biodiversity conservation by examining primary research involving racialized and marginalized communities that have been affected by Kruger National Park in South Africa. I conclude that the embeddedness of environmental justice in biodiversity conservation discourse and action will facilitate legitimate participatory planning and integrated resource management in protected areas/parks, and serve to equitably benefit human and wildlife users of the space.

\section{Environmental Justice}

Environmental justice emerged in the 1980s as an area of research that was concerned with racialized neighbourhoods predominantly carrying the burden of environmentally damaging human behaviour, such as landfill sites and toxic and hazardous waste sites. Environmental racism/racialization, a concept that is elaborated below, is one form of the systemic and institutionalized oppression and exclusion that defines environmental injustices. Environmental justice work has since grown to consider such interrelated categories of difference as class, gender, sexuality, age, and ability, which all serve to inform a person's experiences. Further, environmental justice has widened its scope to address questions that include the complexities of peoples' interactions with their surroundings. These interactions include such issues as food security and park/recreation access. 
"Racialization" refers to the ongoing processes through which groups of people become differentiated based on characteristics that become associated with race (Human Rights Equity Office, n.d., p. 6). Therefore, I employ the term "environmental racialization" to problematize institutional and systemic inequalities that persist in biodiversity conservation. Certainly, historical practices of colonial conservation are reflective of environmental racism. The shortfalls of ongoing action in South Africa to incorporate environmental justice into the country's biodiversity conservation methods reflect the continuous processes of racialization.

The prominent American environmental justice scholar Robert Bullard (1999) describes the environmental justice framework as working to "uncover the underlying assumptions that may contribute to and produce differential exposure and unequal protection" (p. 7). Along these lines, I apply the environmental justice framework to assumptions present in decision-making about the biodiversity conservation of Kruger National Park. By doing so, my aim is to provide reason for the unification of what Alastair lles (2002) calls a "disconnect" between conservation outcomes and "the people, places, and livelihoods where biodiversity exists" (p. 243). In other words, conservation goals can be perceived as operating outside a place's history, and that environmental protection does not integrate acceptable traditional human uses.

\section{Environmental Justice and Kruger National Park}

There are over 105,000 protected areas globally (West et al. 2006) and according to Timko and Satterfield (2008) they "remain central to enhancing biodiversity conservation across landscapes" (p.238). West et al. (2006) assert that "protected areas are the material and discursive means by which conservation and development discourses, practices, and institutions remake the world" (pp. 255-256). For this reason, it is important to look at where the power of constructing and disseminating such discourses lie, who determines the actions and to whom they benefit, as well as the institutionalized assumptions and prejudices about the purposes of protected areas. Historically, hegemonic ideals of conservation have not been compatible with local needs in the regions being preserved because the dominant model emerged from colonial approaches to nature and wilderness. In part, colonialism in Africa justified itself by conceptualizing the continent as a primitive place. This belief helped validate the massive displacement of indigenous peoples for conservation. It is, therefore, important for environmental justice to become a part of conservation to rectify past injustices and prevent new ones. 
South Africa's landscape of protected areas continues to illustrate colonial ideals, including the fact that over $13 \%$ of the country consists of private game farms and $6 \%$ is in government run protected areas (West et al., 2006, p. 255). The same processes that established game reserves were carried forward into the construction of national parks, belying a "preservationist notion of conservation" (Cock \& Fig, 2000, para. 18). The humans who had historical access to that land for subsistence and cultural purposes were ignored and excluded. This notion of colonial conservation was disseminated across colonies and informed practicel. Access by marginalized groups to protected areas was consistently limited through "legislation, enforcement, and privatization" (West et al., 2006, p. 257). However, academics have noted a shift in discourse (see Dahlberg, Rohde, \& Sandell, 2010). They recognize governing bodies (both national and international) and NGOs "have revised their policies with an ambition to reconcile conservation and development and promote environmental justice" (210). Post-apartheid South Africa has had its own experiences with this shift as policy changes have been put into action.

\section{Locating Environmental Racism/Racialization in South Africa's History of Biodiversity Conservation}

The history of apartheid in South Africa and its enduring inequitable distribution of natural resources and power contributes to environmental racialization. It has been well-established that South Africa's history of establishing national parks and protected areas involved the displacement of black South Africans, restricted access by this group to park services as visitors and resource users, and reinforced the erasures of cultural identities and presence. Additionally, these practices contributed to economic oppression by legally preventing access to resources in the park that supported communities' livelihoods and by subsequently not providing compensation for those losses or transition to paid labour within the park (Cock \& Fig, 2000; Anthony, 2006; Timko \& Satterfield, 2008). Protected areas in South Africa are not unbiased creations of conservation planning, but are spaces that, in Cock \& Fig's (2000) words, "reflect the relations of power and privilege which have shaped South African society" (p. 23). For example, prior to 1994, protected areas openly reinforced a privileged white minority (Cock \& Fig, 2000) and Kepe (2009) states that "biodiversity conservation in South Africa has been, and continues to be, the domain of whites" ( $p$. 873).

1 In Canada and the United States the history of national parks and protected areas involved displacing Indigenous populations from their land to reserves, including Yellowstone National Park, 
Kruger was established as a national park in 1926, emerging from a small game reserve established by a proclamation signed in 1898 by white president Paul Kruger (Cock \& Fig, 2000; Siyabona Africa, n.d.). It is the second oldest national park in the world with an area close to two million hectares, and it is argued to be "unrivalled in the diversity of its life forms with 147 species of mammals and 507 species of birds" (Cock \& Fig, 2000, p. 22). In 2008, the park had 1,883 permanent employees and 233 temporary employees (Stickland-Munro, Moore, \& Freitag-Ronaldson, 2010, p. 667). In 2007, it reported over one million tourists per year (Anthony, 2007, p. 237). Exclusion based on race is traced as far back as 1902 to the man who became the first warden of Kruger National Park and who forcibly removed indigenous inhabitants from their homes when the park was still a game reserve (Cock \& Fig, 2000). This continued into the apartheid era of the 1970s-1990s (Liu \& Saal, 2001, p. 235) and Tanner, Freimund, and Van Wyk (2010) document that, up until democratization in 1994, essentially all "resource use among local residents for subsistence purposes was ... effectively prohibited" (p. 79). Kruger was exemplary of the systemic forces reinforced by white conservationists whose privileged perspective inhibited the consideration of local needs. They focused primarily on conservation goals, which reproduced colonial understanding of nature and an erasure of local histories. An example of this is the fact that Kruger was constructed on land which indigenous African mining and trading formerly took place (Cock \& Fig 2000).

Up until the 1980s, a single tent was the only accommodation allotted to Kruger's black visitors and the park was accessible assuming the visitor's ability to afford the park's steep access fee (Cock \& Fig, 2000). To this day, access fees exacerbate the difficulty of visiting Kruger and reflect the persistence of apartheid's economic marginalization. Therefore, even though black South Africans can legally access parks, tourists are largely still white South Africans and international visitors (Dahlberg et al., 2010; Kepe, 2009). Notably only 12\% of visitors in 2005 were black (Kepe, 2009). Poverty that exacerbates restricted access to protected areas continues to be an issue for both conservation action and communities attempting to use their services. Specifically, the land west of Kruger is home to two million people in densely populated communities who experience a high incidence of poverty, unemployment, and food insecurity (Strickland-Munro 2010, 669). Past studies have found that black South Africans "feel little sense of ownership of national parks" (Strickland-Munro et al., 2010, p. 664). Since democratization, South Africa has attempted to bridge this disconnect and develop park management practices that benefit racialized local communities. An initial step towards this goal was the creation of South African National Parks (SANP) out of the former National Parks Board in 1997, which had mainly 
consisted of privileged white males (Cock \& Fig, 2000; Anthony, 2006). Both the 1996 post-apartheid Constitution and park management goals reflect a global shift in policy and action, and aim to achieve poverty reduction and biodiversity conservation (Kepe, 2009; Anthony, 2006; Timko \& Satterfield, 2008). SANP has declared that it

is striving to transfer power and control of resources from the minority that had been appointed and privileged by an undemocratic system, to the majority that participates in the new democratic process. It is also directing the benefits of its activities to providing for all South Africans, rather than the more wealthy and privileged sections of society. (Cock \& Fig 2000, p. 24)

SANP's statement demonstrates their intention to incorporate environmental justice into protected area development and biodiversity conservation in postapartheid South Africa, but on-the-ground change shows varying levels of success. A number of scholars (Strickland-Munro et al., 2010; Timko \& Satterfield, 2008; Cock \& Fig, 2000) have developed categories to evaluate the relationship between conservation and equity/justice in Kruger that I consulted in order to structure the arguments of this paper. The categories I use to address the role of environmental justice in relation to Kruger are (a) land ownership and resource use, (b) community participation in park management and decision-making, and (c) justly shared economic and socio-cultural benefits.

\section{The Experiences of Communities Neighbouring Kruger National Park Land Ownership and Resource Use}

South Africa's Land Acts of 1913 and 1936 restricted African land ownership to $13 \%$ of the country's land for $70 \%$ of its population (Cock \& Fig, 2000). The displacement of black South Africans reduced the culturally significant meanings they found through association with traditionally accessed land. Upon democratization, there was an economic, political, and socio-cultural need for land restitution. This culminated in the 1994 Restitution of Land Rights Act that specifies the legal ability of "communities and individuals to file a claim for land from which they had been removed after 1913" (Timko \& Satterfield, 2008, p. 240). There were thirty-seven pending claims at Timko and Satterfield's (2008) time of writing and only one that had been settled. This successful claim, between Kruger and the Makuleke community (Timko \& Satterfield, 2008), resulted in a northern portion of Kruger becoming a contract park in 1998 that is co-managed by park staff and the Makuleke community 
(Dahlberg et al., 2010). ${ }^{2}$ The park staff remains responsible for conservation and the Makuleke community is in charge of tourism (Dahlberg et al., 2010). Dahlberg et al. (2010) point to research by Carruthers (2007) and Fabricius and Collins (2007) that document greater employment opportunities for members of the Makuleke community that has allowed for more investment in education, health, and infrastructure (p. 213). Similarly, Hannah Reid (2001) attributes the success of the Makuleke-Kruger agreement, thus far, to shared goals between the co-managing groups, government support, and legitimacy, despite some unfulfilled capacitybuilding and revenue generation (p. 151). She concludes that the settlement "gives cause for optimism regarding the region becoming economically, ecologically, and socially sustainable" (Reid, 2001, p. 151). The agreement between Kruger and the Makuleke community is a step towards national legitimate participatory planning, equitable integrated resource management, and shared economic and sociocultural benefits. While members of the Makuleke community may not have as much control as they had hoped, the community (a) has more decision-making power through which to exercise their agency, (b) more power to redefine what biodiversity conservation means in their context, and (c) is able to reproduce new cultural identities with respect to their surroundings of this redefinition.

One outcome of the Makuleke-Kruger agreement has been the reintroduction of the Makuleke's limited resource use in the park, for example, their use of medicinal plants (Timko \& Satterfield, 2008). Tanner et al. (2010) report the introduction of limited subsistence-based resource use elsewhere in the park as well (p. 75). This reintroduction is demonstrative of SANP's goal to incorporate environmental justice into its practices. Tanner et al. (2010) studied the perspectives concerning subsistent access within Kruger to natural resources by local communities and park staff. They conducted sixty-seven semi-structured interviews with members of both groups, using a snowball sampling method to recruit participants (Tanner et al., 2010). Their findings for members of local communities reflected the perception of the park "as an opportunity to conserve and learn about nature, as well as a mechanism for generating income and employment" (Tanner et al., 2010, p. 76). Additionally, these respondents "expressed entitlement to the resources in the park," primarily because they depend on them to live, but also because of the country's history of displacement (Tanner et al., 2010, p. 76). Further, some community respondents

\footnotetext{
2 When the area was first made into a game reserve in 1933, the Makuleke community still accessed it, but they were eventually displaced in 1969 (de Villiers, 1999, in Dahlberg et al., 2010, p. 213).
} 
described that illegal, but sustainable, natural resource use was justified, due to the scarcity of resources outside the park, while others worried that this use would dissuade tourism (Tanner et al., 2010). Perspectives of park staff also varied. One opinion was that staff members are "morally obliged to give some limited access to the resources in the park within the confines of conservation" (Tanner et al., 2010, p. 78). Unsurprisingly, other staff respondents believed use of these resources would reduce the park's purpose to sustain biodiversity (Tanner et al., 2010). Most importantly, Tanner et al.'s (2010) study of resource access revealed almost unanimous support for community participation in decision-making. A member of one local community member said, "Even if to only understand their point of view, that will help them [the park staff] to make decisions that will also help the community" (Tanner et al., 2010, p. 77). Overall, respondents from both groups agreed a consultative and adaptive introduction of cautious resource use for subsistence would be appropriate (Tanner et al., 2010).

Tanner et al.'s study reveals that even within supposedly like-minded groups of people there are differences of opinions. However, between opposing groups of people, a consensus for future action can be reached. This is significant because assumptions about each group's perspectives are challenged and a new definition of equitable resource use can be achieved. Tanner et al.'s research is also important for the finding that achieving a transparent process will lead to legitimacy, and benefit biodiversity when maintenance of the park's resources is meaningful to all stakeholders. The effects of restricted access rights caused "an erosion of local knowledge" (Dahlberg et al., 2010, p. 211) and weakened local communities' "engagement with agencies of environmental management as well as with environmental concerns in general" (Dahlberg et al., 2010, p. 211). Appropriate and meaningful consultation and partnerships can, therefore, work to restore knowledge systems and equitable resource use.

\section{Community Participation in Park Management and Decision-Making.}

Tanner et al.'s study (2010) illustrates the importance of the meaningful consultation and participatory planning that SANP has begun to practice. SANP began to engage local communities through forums in the 1990s and community involvement has grown to seven "participatory communication structures" (Anthony, 2007 , p. 237) representing many villages. The greater community involvement sought by Kruger reflects the notion that conservation shortcomings are due to top-down practices that are not supported by local communities. West et al. (2006) determine 
top-down regulatory bodies to be ineffective because they do not "appreciate, or work with, local practices and interests" (p. 260). As a result, the top-down regulations are not representative of local community needs and imposed conservation regulations are less likely to be followed. Thus, successful integration of grassroots objectives with top-down conservation goals is required to realize legitimate community participation. To evaluate Kruger's inclusion of and consultation with local communities, Anthony (2007) investigated the attitudes towards the park by 240 households from thirty-eight communities located directly west of Kruger. His results revealed that $72.9 \%$ of respondents had never been inside the park (Anthony, 2007). Despite this, the majority of participants in the study expressed positive responses concerning their perception of the park (88.7\%), their household's close proximity to it (70.8\%), and the park's effect on their community (59.6\%) (Anthony, 2007). Yet $77.9 \%$ of participants expressed a negative response when asked whether households had benefitted from Kruger (Anthony, 2007). Additionally, slightly less than half (43.3\%) believed the park authorities did not consider local perspectives and desires in their decision-making (Anthony, 2007).

Anthony's (2007) starkly mixed results reappear in Timko and Satterfield's (2008) evaluation of equity in Kruger. These researchers examined the park's forums, designed to be spaces for consultation between the Park and local communities, and noted several sharp contradictions (Timko \& Satterfield, 2008). For example, one local respondent believed the meetings were a success because employment opportunities had increased (Timko \& Satterfield, 2008). This is reflective of the park's aim to employ more people from local communities. However, another participant said that despite consultation, local opinions had not resulted in changes on the ground (Timko \& Satterfield, 2008). One case where the park did not act upon local needs is with respect to damage-causing animals that regularly escape through Kruger's enclosures ${ }^{3}$. Local community members who participated in Anthony's (2007) research articulated that there had been little response by the park to prevent this from reoccurring and that "affected farmers [were] not being financially compensated for losses, despite promises that compensation would be forthcoming" (p. 242). The lack of follow-through by Kruger for compensation contributes to an atmosphere of illegitimacy and is not helpful towards overcoming the barrier of mistrust that has been established through years of racialization and "the park's colonial history" (Strickland-Munro et al., 2010, p. 667). Furthermore, concerns about

$312.1 \%$ of respondents had been affected by damage-causing animals who escaped from the park in the last two years (Anthony 2007, 239). 
Kruger's lack of action may create tension in local communities towards the escaped animals who are detrimental to agricultural production. This frustration and lack of legitimacy removes households' focus on prioritizing conservation. Thus, Kruger should continue to expand co-management agreements, to engage in participatory planning for the park, and to follow through on these in its management practices.

\section{Economic and Socio-cultural Benefits}

Kruger has been working towards "building local support for conservation and improving access to national parks by local communities" (Dahlberg et al., 2010, p. 213). It has done so through environmental education and cultural activities, especially educational opportunities targeting youth (Dahlberg et al., 2010). These work to address unequal access to the recreational services of the park (Cock \& Fig, 2000). According to Kepe (2009), the park has followed a recent global pattern of "making poverty reduction projects a central feature in conservation policy implementation" (p. 873). This is evidenced by projects aimed at increasing direct and indirect employment in the park's neighbouring communities. While direct and indirect efforts have seen some success, far more engagement and an evaluation of reasons for ineffectiveness are required.

A study by Anthony (2007) revealed gaps between the goals of educational outreach programs and the accessibility of their services to members of local communities. For example, despite the fact that Kruger has attempted to increase local youths' knowledge of the park, especially in terms of the park's role in biodiversity conservation, just over half of Anthony's respondents (53.3\%) expressed neutral responses regarding Kruger's "community development programs" (Anthony, 2007, p. 240). In Anthony's (2007) study, heads of households were surveyed where possible and were given the opportunity to elaborate on their positive, neutral, or negative responses. Anthony (2007) felt that the extent of neutral, perhaps indifferent, responses was problematic given the fact that communities were established in the areas west of Kruger for twenty-five years and outreach programs had started a decade ago. Given that the circumstances were well-established, Anthony (2007) implies that more and stronger positive sentiments towards the outreach programs would be expected and the lack thereof is indicative that changes need to be made. Therefore, not only should the capacity of the programs be increased, but their design must also do more to consider the country's history. 
Kepe (2009) suggests that "education and training of blacks in conservation is seen as the most strategic way to redress past imbalances on this issue" (p. 874). However, he warns that prevailing ideas and meanings of conservation in the park historical context can still be reproduced through training and environmental education efforts (Kepe, 2009). Kepe proposes this is because knowledge transfer has not yet reached "a point where cultural diversity is fully integrated to the different understandings of what the environment and its conservation means to all South Africans" (Kepe, 2009, p. 875). Therefore, it is important to incorporate local communities' meanings of conservation and include grassroots components in environmental education. Not doing so leaves colonial "assumption[s] about black people's knowledge about and interest in conservation" unchallenged (Kepe, 2009, p. 876). Finally, Kepe (2009) suggests that including the perspectives of local communities can be accomplished by openness about racialized ideas concerning conservation, and can lead to definitions representative of black South African's ideas. Acknowledging a place's history is necessary to avoid the paternalistic tendencies of environmental education. This is relevant when considering the services of protected areas and their potential ability to either reinforce historical racialized notions of conservation, or to redefine them.

Efforts to increase employment opportunities for local communities predominantly revolve around tourism. Timko and Satterfield (2008) identify support for local entrepreneurship as including:

building small shops for local producers to sell their crafts at four NP [national park] gates and training community members to run the businesses; a contractor development programme where contractors are trained to run their own businesses; and a guideline that those winning tenders for construction in the NP must hire locally with SANParks maintaining and supplying a list of people who are employable as seamstresses, plumbers, thatchers and electricians. (pp. 247-248)

Anthony (2007) suggests that there is higher evaluation and estimation of park benefits within households where individuals directly employed by the park reside. However, there are mixed opinions expressed in the literature on whether Kruger has benefitted local communities. First, Strickland-Munro et al. (2010) illustrate a sense of nepotism in direct hiring for Kruger because, "for example, the employment of locals is favoured for special events held within the Park and for contract works," but the same does not hold true for long-term, stable, consistently well-paid positions (p. 673). Similarly, Anthony (2007) presents the opinion of local communities that Kruger does 
not do enough to advertise employment opportunities. Further, work in Kruger for members of racialized communities predominantly consists of unskilled and semi-skilled labour (Strickland-Munro et al., 2010, p. 664). These patterns reflect the circumstance of racialization in the region and the country's history of apartheid. Park management's assumptions about local communities' abilities and knowledge must be challenged more strongly, both from within management and by local communities, in order for environmental justice and shared benefits to be achieved.

Related to the broader issues of employment are the negative effects of tourism, which include economic dependency and local communities' unfulfilled expectations of financial benefit (Strickland-Munro et al., 2010). Dissatisfied perspectives reflect the fact that, although tourism has led to greater employment, the demand for work exceeds the supply (Strickland-Munro, 2010; West et al., 2006). Strickland-Munro et al. (2010) examine the socioeconomic impacts of tourism at Kruger in two of the park's neighbouring communities to the west. In general, respondents felt the park was "for tourists, not for them" (Strickland-Munro et al., 2010 p. 672). However, there was a range of sentiments. For example, Strickland-Munro et al. (2010) found a correlation between direct and indirect employment and a "sense of ownership of the Park" (p. 672). One respondent stated, "I'm proud because I'm just close to the Kruger National Park which means it's also mine" (Strickland-Munro et al., 2010, p. 672). Furthermore, Strickland-Munro et al. highlight that, while "tourism can contribute to cultural exchange and revitalising old cultures, traditions, languages and arts," it can also negatively and unintentionally lead to "the marginalisation of locals to jobs of lesser importance, loss or misuse of cultural artefacts, perceptions of cultural exploitation and commoditisation of culture" (Strickland-Munro et al., 2010, p. 665).

Relatedly, West et al. (2006) propose that tourism reproduces "static and essentialist constructions of local people," but that it can also allow people to find new meanings in their surroundings (p. 262). The ways in which cultural/historical sites represent the local and racialized communities near Kruger must demonstrate awareness of the country's colonial history and be conscious of who has the power over relevant discourses and how they are disseminated. If a consciousness regarding discourse is not achieved, a lack of identification with the park by local communities is almost certain. To speak to this, Kepe (2009) has likened the role of protected areas to "'welfare' hand-outs - from the white majority of visitors, to the black majority of the local poor" (p. 876). The power relations and history of apartheid cannot be ignored and the transfer of knowledge about racialized communities in South Africa must be 
actively pursued in order to redress environmental injustices. Throughout this process, it is essential that the agency of those communities be recognized.

Curio stalls are a space where the negotiation of cultural strengthening and appropriation are contested. They are usually set up on entrance roads and they characterise a popular form of the park's indirect employment opportunities and economic benefits (Strickland-Munro et al., 2010). Scherl and Edwards (2007) and Cock and Fig (2002) argue that the local production of crafts, artisanal work, and services sold at curio stalls create spaces and opportunities for local cultural values and practices "in relation to the land" to be reproduced and their meanings strengthened (as cited in Strickland-Munro et al., 2010, p. 674). Scheyvens (1999) goes even further, stating that these values can be psychologically empowering to a community. Thus, it is strongly supported that curio stalls can be a tool in land reclamation and redefining local connections with the park. Conversely, they can be problematic because they involve the commodification of local and racialized cultures and could give way to an essentialist view of these groups, resulting in cultural appropriation of indigenous values and practices by tourists.

Artisan crafts, for instance, can be relegated to "low" art forms and incorporated into colonial ideas about "primitive" artistic productions that reproduce paternalistic notions of "noble savages." From this perspective, colonial conservation in the present-day has seen indigenous peoples "reappear" in the spaces from which they were erased, "as purveyors of arts and craft, entertainment, and other services required by visitors" (West et al., 2006, 259). This notion was reflected in one community member's response about the balance of economic benefits of curio stalls expressed in Strickland-Munro et al.'s (2010) study. The participant said, "they [tourists] stop at the little markets which are here to buy ... but otherwise we don't communicate with them outside" (Strickland-Munro et al., 2010, p. 670). The separation some locals feel between themselves and the tourists can be linked to their disconnect from the park itself. Increasing the economic and socio-cultural benefits is required to redress issues of economic oppression and erasure of local cultures and identities. The creation and support of spaces for members of local communities should be given prominence. These efforts are important for biodiversity conservation as feelings of closeness, pride, and ownership through employment and environmental education encourages support for the park's conservation efforts (Anthony, 2007, 241; Kofinas \& Chapin, 2009, in Strickland-Munro et al., 2010, p. 674). 


\section{Conclusion}

Just as unequal access to resources, services, and power prevail on the basis of race in South Africa, these same barriers are reflected by the persistence of structures in Kruger National Park. A national park/protected area represents a microcosm that has the ability to reproduce the inequalities found within the larger society. Kepe (2009) argues that there has not been explicit action in South Africa that connects race to the country's history of conservation and that without an honest recognition of the past there can not be equitable biodiversity conservation planning. Dahlberg et al. (2010) argue that "the persistence of an entrenched conservation ideology has meant that more recent efforts to promote environmental justice have been frustrated and spaces of inequality continue to be reproduced" (p. 220). The dominant colonial conceptualizations of conservation have persisted: the "original institutions are still in place - relatively unchanged - and with them a centralised and top-down management structure is maintained" (Dahlberg et al., 2010, p. 220). There remains a glass ceiling over powerful positions within park management, and employment in the park for local communities is commonly low-skilled.

The potential for inequalities and racialization to be reproduced persists. Actors in local communities negotiate their positions (a) through land claims, (b) by legally and illegally accessing resources within the park, (c) pursuing direct and indirect employment by the park, and (d) by reproducing meanings they find within their surroundings. Kruger remains a contested space and it is necessary for those who hold privileged positions within park management to acknowledge and renounce their privilege in order for environmental justice to be legitimately embedded in future processes of conservation. As a result, this would facilitate stronger land ownership and resource use, increased community participation and decision-making, and greater economic and socio-cultural benefits. Not only should environmental justice be embedded within the practices of existing parks, such as Kruger, but its discourse should be a part of the broader discussion around protected areas and conservation for development of future parks. lles (2002) writes that "equity grows out of the development that people choose, in terms of their histories, times, and places" ( $p$. 251), but that is only if all peoples' perspectives and decisions have a platform to be heard and their positions respected. 


\section{References}

Anthony, B. (2007). The dual nature of parks: Attitudes of neighbouring communities towards Kruger National Park, South Africa. Environmental Conservation, $34(3), 236-245$.

Bullard, R. D. (1999). Dismantling Environmental Racism in the USA. Local Environment, $4(1), 5-19$.

Cock, J. \& Fig, D. (2000). From colonial to community based conservation: Environmental justice and the national parks of South Africa. Society in Transition, 31 (1). doi: 10.1080/21528586.2000.10419008

Dahlberg, A, Rohde, R., \& Sandell, K. (2010). National parks and environmental justice: Comparing access rights and ideological legacies in three countries. Conservation and Society, 8(3), 209-224.

Human Rights and Equity Office [HREO]. (n.d.). Understanding racialization: Creating a racially equitable university [booklet]. Retrieved from https://www.voguelph.ca/hreo/system/files/UnderstandingRacialization.pdf

Iles, A. (2009). Differential obligations: Equity under the biodiversity convention. Leiden Journal of International Law, 16(2), 217-251. doi:10.1017/S0922156503001134

Kepe, T. (2009). Shaped by race: Why "race" still matters in the challenges facing biodiversity conservation in Africa. Local Environment, 14(9), 871-878.

Liu, A. \& Saal, D. S. (2001). Structural change in apartheid-era South Africa: 1975-93. Economic Systems Research, 13(3), 235-257.

Reid, H. (2001). Contractual national parks and the Makuleke community. Human Ecology, 29(2), 135-155.

Scheyvens, R. (1999). Ecotourism and the empowerment of local communities. Tourism Management, 20, p. 245-249. 
Siyabona Africa: Your Informed African Travel Partner. (n.d.). History of Paul Kruger, Kruger National Park. Retrieved from http://www.krugerpark.co.za/Krugerpark_History-travel/paul-krugerhistory.html

Strickland-Munro, J. K., Moore S. A., \& Freitag-Ronaldson, S. (2010). The impacts of tourism on two communities adjacent to the Kruger National Park, South Africa. Development Southern Africa, 27(5), 663-678. doi:1 $0.1080 / 0376835 X .2010 .522829$

Tanner, R., Freimund, W., \& Van Wyk, E. (2010). Legitimacy and the use of natural resources in Kruger National Park, South Africa. International Journal of Sociology, 40(3), 71-85. doi: 10.2753/IJS0020-7659400304

Timko, J. A. \& Satterfield, T. (2008). Seeking social equity in national parks: Experiments with evaluation in Canada and South Africa. Conservation and Society, 6(3), 238-254.

West, P., Igoe, J., \& Brockington, D. Parks and peoples: The social impact of protected areas. Annual Review of Anthropology, 35(1), 251-277. doi:10.1146/annurev.anthro.35.081705.123308 